\title{
Representational model on Moodle's activity: learning styles and navigation strategies
}

Open Access

\author{
Sandra Meza-Fernández ${ }^{1 *}$ and Agustín Sepúlveda-Sariego ${ }^{2}$
}

\footnotetext{
* Correspondence: smeza@uchile.cl ${ }^{1}$ Emilia Téllez 5253, Ap. 179, Ñuñoa, Santiago, Chile

Full list of author information is available at the end of the article
}

\begin{abstract}
This paper attempts to describe the conditions related to the representation of 63 navigational paths carried out on Moodle's platform. The hypothesis that we advance is that learning styles determine the mode in which users browse through websites. The post-observational notes and the analysis of logs (register of users' activity) indicate two main facts: on the one hand, the elaboration of a tool that is able to convert log files into graphs that could be visualized as courses of educational browsing. On the other hand, the confirmation of the relation between ways of learning and styles of browsing, giving rise to a method that anticipates choices made by users on the digital platform.

There has been stated that assimilative and convergent learning students solve the assigned task consulting, preferably, the content modules on communicative interaction. For their part, accommodating learning students follow precise instructions and rely on his peers' activity. Finally, divergent learning students tend to prefer collaborative activities and they also help each other.

The practical application of the results aims at the usefulness of the findings in university education context, which can be used in the elaboration of quality assessments and the identification of the needs of educational mediation.
\end{abstract}

Keywords: Analysis for log, Learning style, Moodle, Navigational paths, Representation of browsing

\section{Introduction}

The concept of Browsing in computerized educational contexts is frequently presented in general terms. A considerable amount of expressions enunciate figures as a "journey through a computerized labeled setting" or "continuum of decisions and action" (Amadieu and Tricot, 2006: 12). Nevertheless, the notion of a journey related to a digital and pedagogical navigation implies the distinction between the functions and the components of that journey.

We define navigation Web as an activity that involves an intentioned pedagogical journey through a semiotic and cognitive space, by means of the completion of a task. This notion points out to, on the one hand, the mouse-clicking that allows to connect to the computer interface, and on the other hand, to the footprint that this action produces. A footprint that is part of a flow and that also expresses an educational intentionality, starting in the process of planning the course, and performed by the

(c) The Author(s). 2017 Open Access This article is distributed under the terms of the Creative Commons Attribution 4.0 International License (http://creativecommons.org/licenses/by/4.0/), which permits unrestricted use, distribution, and reproduction in any medium, provided you give appropriate credit to the original author(s) and the source, provide a link to the Creative Commons license, and indicate if changes were made. 
same students. In this sense, we define as navigational path to the pedagogical event (Tchounikine, 2009) in which students choose a determined strategy in order to carry out the task.

\section{Development Learning styles}

The theory on learning styles emerges as a continuation of studies related to cognitive styles focusing on individual differences at a global level and also in a laboratory context. Among the various definitions associated to learning styles, Keefe (1988) points out that learning styles are cognitive, psychological and affective footprints. Honey and Mumford (1992) define learning styles as a description of attitudes and behaviors that determine students' learning preferences.

The Learning Style Inventory (Kolb and Kolb, 2005a, b) determines learning styles according to predominant or key factors: CE (concrete experience), RO (reflective observation), AC (abstract conceptualization), and AE (Active experimentation). These different factors are related to different approaches to learning: Diverging, Assimilating and Accommodating.

\section{Elements involved in digital navigation}

The notion of digital website demands the distinction of its components in detail. In the first place, websites contain modules which are the resources proposed in order to mediate in the students' task accomplishment. In the second place, it is necessary to distinguish the participants and their activity, giving place to the navigational paths that those actors go through when browsing through the website. Equally important is to determine in advance the possibilities of browsing students could go through (Fig. 1).

\section{Representation of digital navigational paths}

The visual representation of the digital navigational paths or roads is carried out through the digital footprints taken from users' logs (register of users' activity on websites) and graphs' instrumentation. The modelling phase converts Moodle modules into nodes and the transition of those nodes into arcs, displaying the required task by means of arrows that indicates the completion of the task and the directions followed by the user. In the case illustrated above, the node corresponds to a given functionality, and as a whole, accounts for the use of the resources proposed, while the arc shows connections between modules. The different functionalities are grouped into 12 modules, which are expanded in order to account for a higher use frequency. Likewise, the arcs are widened in order to give account for a higher number of connections.

Figure 2 shows a route translation program that allows for the reading of graphs and, consequently, it interpretation. This instrument should be created because the existing programs -cartographic database (DB) or geographical representation tools- could not be adapted to the case of investigation, which includes the space that will be mapped as the human behavior in that specific space. The graph depicted in Fig. 2 shows the navigational paths that 3 students went across. Modules are illustrated by means of different colors, being the red spots the places that students visited the most. 


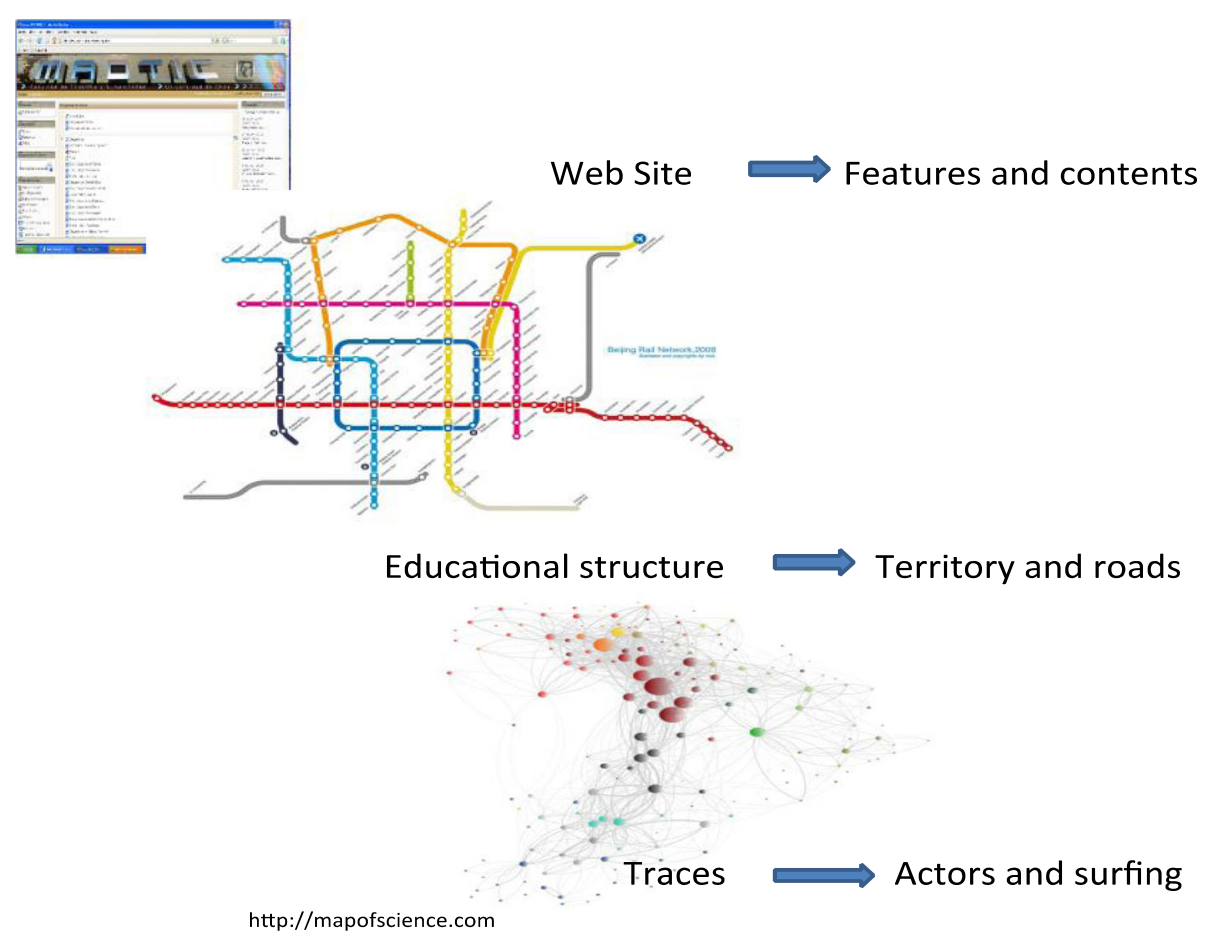

Fig. 1 Components of digital navigation. Source: Meza, 2014

\section{Methodology}

The population is 63 university students of 5 courses, 16\% Spanish speakers and 84\% French speakers. We have selected 5 choices per student, between the 2 nd and the 6 th click. The sample corresponds to the ones who selected the course view module by doing the 2 nd click on the mouse. They were 31 out of 63 cases.

The analysis of the data shows the navigational paths that students went through at the very starting point of the task (particularly irrelevant given no comparative

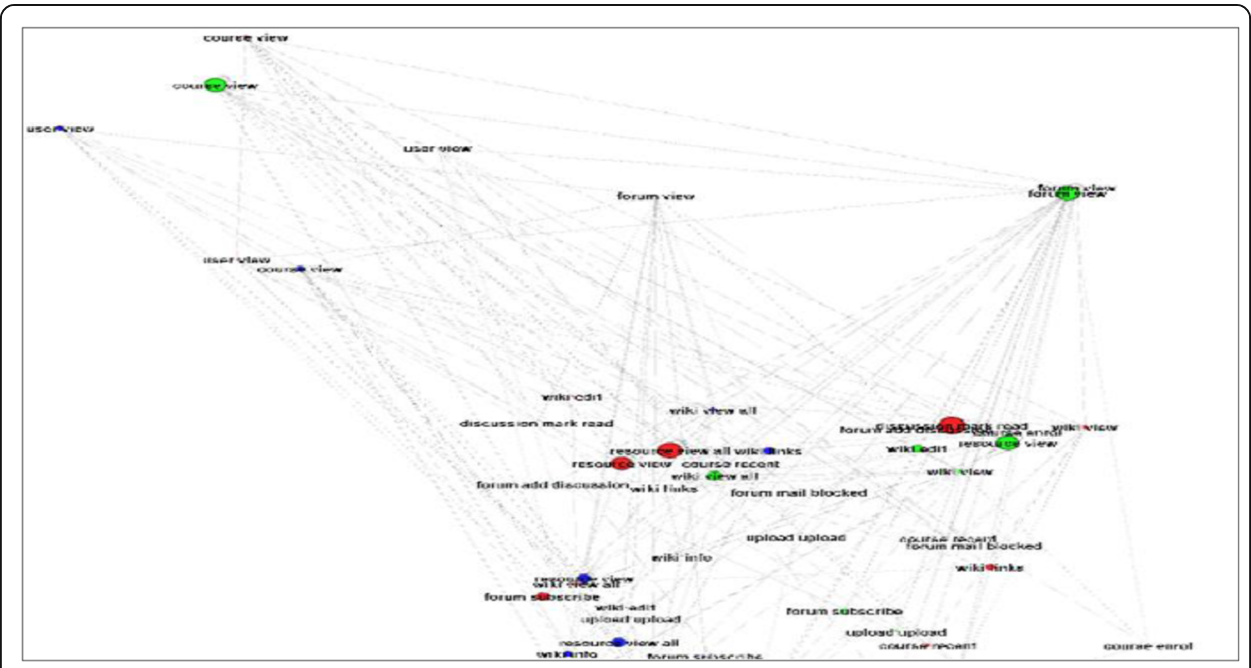

Fig. 2 Graphic display of digital routes from 3 students, on software Gephi Software Gephi: https://gephi.org. Source: Meza, 2014 
research). In order to accomplish this, results from previous work were partially utilized (Meza, 2012):

1) The definition of 4 students' profiles according to a task classification.

2) The definition of a navigation variable: the referential navigational paths ${ }^{1}$

3) The definition of navigation modes according to the intersection between four tasks and four users' learning styles.

The diagram (Fig. 3) used to illustrate this is an adaption from the Learning Style Inventory LSI (Kolb and Kolb, 2005a), which integrates four views that are in connection with Moodle modules. There are two groups of tasks classified according to their global or local characteristics. On the one hand, global tasks are classified according to students' reception regarding administrative and familiarization tasks related to the website (Course view, User, Data view, Download and Data add); and on the other hand, local tasks are associated to the course's main theme by means of pedagogical modules (Glossary, Blog, Forum, Resource, Glossary add, Forum add, and Wiki edit).

Reception modules (Fig. 3):

1. Global reception - panoramic view: Course view, User and Data view modules (M1, M2 and M6 respectively).

2. Local reception - reading function: Glossary view, Blog view, Forum view and Resource modules (M3, M4, M5 and M8 respectively).

\section{Production Modules:}

3. Global production - peripheral view: Download and Data add modules (M7 and M9 respectively).

4. Local production - writing function: Glossary add, Forum add and Wiki edit modules (M10, M11 and M12 respectively).

We are using the components to represent the route of student " $\mathrm{X}$ " in the course " $\mathrm{F}$ ". This effective browsing is compared with the expert route of the course given by the class teacher. This expert route complies with the shortest most efficient way to accomplish the prescribed learning task.

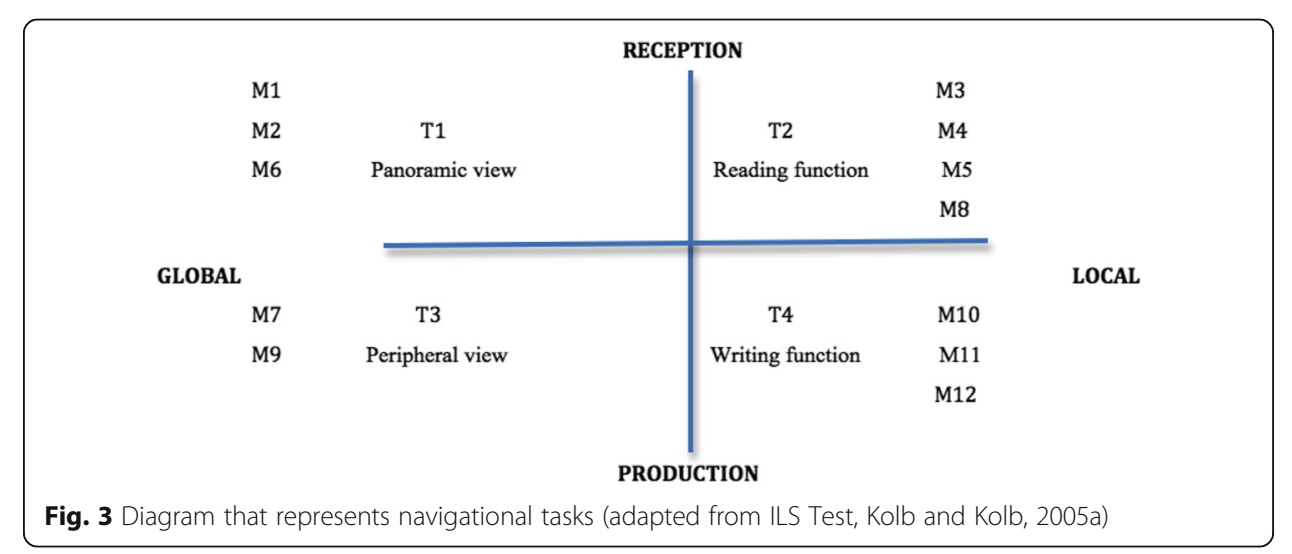


Expert browsing:

- Start: from M1 (exploration of the page) to M8 (resources).

- Step/click 1-2: from M8 (resources) to M5 (forum).

- Step/click 2-3: from M5 (forum) to M11 (writing in the text editor).

In other words, we compare two browsing, the expert one and the novice (inexperienced) one (Fig. 4).

\section{Analysis}

\section{Assimilative learning style}

The navigational paths of 11 students reveal a preferential activity on Reception modules. On the contrary, modules as Glossary and Blog tend to be less preferred. In the case of the Production modules section, there is not much activity registered. This evidence indicates that this type of students preferred the Production modules' activities. This fact points out that assimilative learning student activities were focused on reception and the global factor.

The activity registered by assimilative students is the most dynamic among the four learning styles. This shows their interest in activities related to AC (Abstract conceptualization) and RO (Reflective observation). This fact is observed likewise in the choice of Resource module, at the second click made by half of the group. Nevertheless, assimilative students do not lack of pragmatism; they also have chosen modules such as Forum and Data view, choices that tell us something about other students' activities. In this sense, 9 students checked the instructions of the task at the 3rd click; fact that shows their commitment to carry out the task. The only problem was that half of the group did not understand the instructions, due that they clicked again on the instructions sections at the 5 th click.

In general, assimilative students prefer functions that contain information about the topic or the task to develop such as Resource module, particularly consulted at the 4th click.

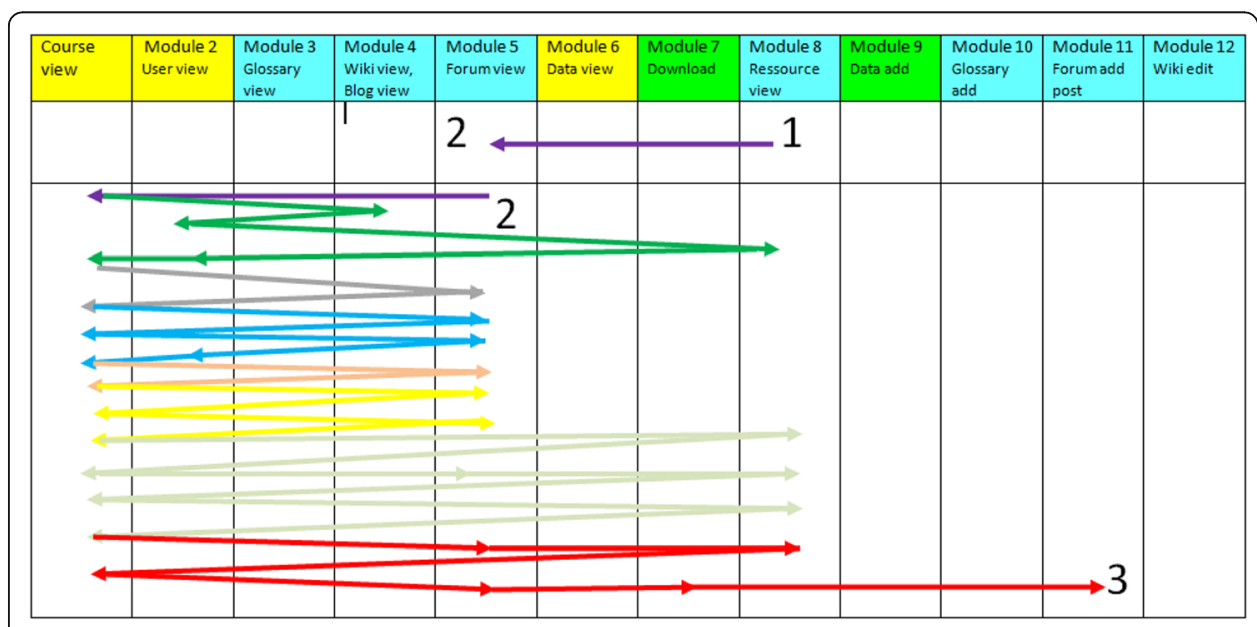

Fig. 4 Diagram Real browsing of Student " $X$ " (Colours represent the different days) 


\section{Accommodative learning style}

The set of navigational paths from 5 students shows an advanced activity on the Reception modules; Forum and Resource, as the Course view option tend to be clearly preferred. On the contrary, there is no activity registered on the Production modules. This fact indicates that students from this group tend to prefer equally local and global reception-activities. Accommodative learning students' preferences rely mainly on the interconnected functions Forum and Course view. Those activities are classified under the domain of $\mathrm{CE}$ (concrete experience) and $\mathrm{AE}$ (active experimentation) factors. Considering their ability to adapt to specific circumstances, the concrete prescribed tasks could have facilitated the development of those tasks on the website. Nevertheless, the tendency to solve problems intuitively is not reflected on the students' choices (Blog and Forum), who rely more on information provided by other students than on their analytic aptitude.

\section{Convergent learning style}

The set of navigational paths from 5 students shows a preference-although not exclusive- towards the Reception modules. Nevertheless, modules such as User, Blog and Forum show little activity. The activity registered on the production modules is not significant, yet this illustrates an interesting point: the activities on the production modules are related to productive functions. It is possible to interpret that the work registered by Convergent learning students is focused mainly on receptive activities, although equally on global and local factors.

Convergent learning students' activity is equally distributed on Production and Reception modules. According to their dominant aptitudes on AC (abstract conceptualization) and $\mathrm{AE}$ (active experimentation), these students tend to prefer the Resource module. Their knowledge is organized according to specific tasks, without being interested on others' activity or relying on others' help. Indeed, it is possible to observe that these students almost never clicked on communication modules such as Blog or Forum. Furthermore, this was the only group of students that never clicked on the User module.

\section{Divergent learning style}

The set of navigational paths retrieved from the activities of 10 students shows a preference towards the Reception modules; there is a high level of activity registered on Resource and Course view modules and less activity registered on User, Glossary y Data view. Notwithstanding this, this group of students selected all modules.

The activity registered on Production Modules is less but more diverse and significant than in the other groups. Divergent learning students were the only ones that clicked on Glossary add and Forum add options. This fact shows that the activity of the group is mainly focused on reception and global factors.

The activity carried out by divergent learning students is the most dynamic among the four learning styles. According to their characteristics, it is possible to distinguish two features: 1) Students from this group perceive concrete situations adopting various perspectives, being more attracted to situations that involve OR factors. These students explore all the modules, except for the Download and Writing sections. 2) Students from this group are interested in the activity registered from other students, as can be shown in the checkup of what other students upload, Data view, and the instructions displayed on the Course view module. 


\section{Discussion}

Digital learning systems have been rapidly adopted due to their flexibility, which encourages the construction of individual learning achievement strategies (Wang et al., 2000). Nevertheless, the question concerning the efficacy of the systems described above requires a close examination of the relation between the students' navigational paths and the learning results. The investigations conducted on this ground show that the holistic (panoramic navigation) and serial (thorough navigation) cognitive styles (Lee et al., 2005), affect such behavior. Nonetheless, they do not seem to show a direct relation to learning results.

Thus, it is necessary to lay down the theoretical foundations in order that this relation may be produced. This fact implies to make visible the navigation routes in order to interpret them.

If we start from Jonassen and Grabowski's ideas (1993) on cognitive styles- who point out that people with holistic style possess a higher ability to concentrate on multiple tasks, as compared to people with serial style who can focus on a single task- and we add the construction of a hierarchical chart of information (oriented to people with holistic style) and a preference for the semantic organization of contents (oriented to people with serial style), there may be useful interpretations for the elaboration of an information chart based on the students' dominating learning style.

Other investigations conducted on these grounds highlight the usefulness of different variables, such as the use of multiple learning methods, aiming to consider all individual cognitive traits (Saarikoski et al., 2001) and the dominant learning style (Alonso, et al., 1999). All these facts mentioned above allowed for defining the scopes taken into consideration for the empirical design carried out. Other aspects show problems level curriculum design, instructional methods, assessment and student guidance (Curry, 1990).

According to Baccino's model scanpath (2004), the activity of web browsing and navigation obeys to a sequential movement through the website's visual space and also to a quick overview on useful information.

Furthermore, McAlesse (Le Crosnier, 2008) propose 5 hypertext-reading strategies, and also a classification of work functions: Skimming, scanning, investigating, explorating and wandering. The type of navigational path of beginner users is characterized as an erratic navigation. Amateur users possess some knowledge on websites and information technology (IT).

Based on a diagram that represents the functions and the starting module at expert level, is that navigational paths could be described for every learning style. This model allows for the description of navigational syntax, showing 6 possible navigational behaviors: academic, circular, combined, social, mimic, and strategic behaviors. (Meza, 2014).

\section{Results}

The navigational competence of assimilative learning students is related to the combination of abstraction factors, in relation to the contents of $\mathrm{AC}$ and $\mathrm{RO}$ that allows for the completion of the task. For diverging learning students, approaches that consider the experience and experimentation of the users could explain their competence in the context of a digital space task. Regarding the navigational paths, assimilative as well as converging learning students tend to prefer paths which are functional to the 
achievement of the task. Besides, both groups of students tend to be less interactive in the context of browsing pedagogical functions. On the other hand, Accommodative learning students tend to be more pragmatic when faced to the completion of a task; fact that allows them to look for concrete premises and rely on information provided by other students. On the same line with a more visible tendency, diverging learning students spend a considerable amount of time examining other students' activity. They spend the rest of the time recognizing the website, showing interest on all resources and modules.

Finally, it can be pointed out that outlining profiles and behaviors facilitates its interpretation, allowing for the possibility of recognizing an erratic navigation. The erratic navigation, under the premise of a given learning objective, could be the symptom of lack of confidence or comprehension. The answer to this problem could be fostered by the notion of efficacy on a navigational path (Bastien and Tricot, 2008), being measurable and identifiable through nodes of the navigational path. This could also be useful in the analysis of navigation rates and to reach to the comprehension of the blockades of learning of the students of all the educational levels. All the elements stated above allows for more precise interpretation on the behavior in virtual spaces related to learning.

\section{Endnotes}

${ }^{1}$ Referential navigational paths correspond to the activity performed by an expert on the subject. In this case, we consider the class teacher as the expert.

Authors' contributions

AS participated in interpretation of results and drafted the manuscript. SM carried out the analysis of log and representation of 63 navigational paths. All authors read and approved the final manuscript.

\section{Authors' information}

(Universidad de Chile) is a language teacher, master sciences and PhD in sciences of the education. Currently, she is employed as researcher of Department of Pedagogic Studies and the Magister at Education, IT Educational mention, at Universidad de Chile. Her research interests are based on the characteristics of the representation of tours of web browsing in educational sites. She has published three articles and a book. From 2012 she has taken part in 6 national and Latin-American congresses, and from 2009, in 14 international congresses (For naming a few; in Austria, Bulgaria, Spain, France, Norway, Poland, Switzerland).

(Universidad de Chile). Master Sciences in Biology, University of Chile, Master in University Education. Currently, he works as a free-lance professor in different universities in areas of pedagogy in science, basic education, special education, and eco tourism. His research interest is on the relation between theories of learning and their neurophysiologic animal navigation-based learning. Agustín has more than 30 years of teaching experience in Scandinavia, Turkey, Bolivia, Chile and Colombia. He is an expert on Permaculture, ecovillages and transition towns, disciplines in which techniques of popular and informal education with grass-roots organizations at international level are considered.

Competing interests

The authors declare that they have no competing interests.

\section{Publisher's Note}

Springer Nature remains neutral with regard to jurisdictional claims in published maps and institutional affiliations.

Author details

${ }^{1}$ Emilia Téllez 5253, Ap. 179, Nuñoa, Santiago, Chile. ²Brown Norte 230 apt 302, Nunñoa, Santiago 7790569, Chile.

Received: 20 December 2016 Accepted: 8 March 2017

Published online: 01 June 2017

References

Alonso, C. M., Gallego, D. J., \& Honey, P. (1999). Los estilos de aprendizaje. Procedimientos de Diagnóstico y Mejora. Bilbao: Ediciones Mensajero.

Amadieu, F., \& Tricot, A. (2006). Utilisation d'un hypermédia et apprentissage: deux activités concurrentes ou complémentaires. Psychologie Française, 51, 5-23. 
Baccino, T. (2004). La lecture électronique. Grenoble: Presses universitaires.

Bastien, C., \& Tricot, A. (2008). L'évaluation ergonomique des documents électroniques. En A. Chevalier and A. Tricot, Ergonomie des documents électroniques. Paris: PUF.

Curry, L. (1990). A Critique of the Research on Learning Styles. Educational Leadership, 48(2), 50-56.

Honey, P., \& Mumford, A. (1992). The Manual of learning styles. Maidenhead: Peter Honey.

Jonassen, D., \& Grabowski, B. (1993). Individual differences and instruction. New York: Allen and Bacon.

Keefe, J. (1988). Development of the NASSP Learning Style Profile. In Keefe, J. (Ed.). Profiling and Utilizing Learning Style. Virginia: National Association of Secondary School Principals, 1-21.

Kolb, A., \& Kolb, D. (2005a). The Kolb Learning Style Inventory, Version 3.1 Technical Specifications. Boston: Haygroup. Kolb, A., \& Kolb, D. (2005b). Learning Styles and Learning Spaces. Acad Manag Learn Edu, 4(2), 193-212.

Lee, Y., Grill, S., Sanchez, A., Murphy-Ryan, M., \& Poss, K. (2005). Fgf signaling instructs position-dependent growth rate during zebra fish fin regeneration. Development, 132(23), 5173-5183.

Le Crosnier, H. (2008). A l'ère de l'«informatique en nuages. Paris: Le Monde Diplomatique.

Meza, S. (2014). Enseigner et apprendre en ligne: vers une sémiotique de la navigation Web. Une étude exploratoire. Sarrebruck: Presses académiques francophones.

Meza, S. (2012). Proceedings of the 10th World Congress of the International Association for Semiotic Studies (IASS/AIS). Universidade da Coruña (España) (pp. 1911-1920).

Saarikoski, L., Salojärvi, S., Del Corso, D., \& Ovcin, E. (2001). Un environnement pour le développement de l'éducation axée sur l'apprenant sur mesure Packages. Kumamoto: ITHET.

Tchounikine, P. (2009). Précis de recherche en ingénierie des EIAH. Grenoble: Laboratoire d'informatique de Grenoble.

Wang, P., Hawk, W., \& Tenopir, C. (2000). Users' interaction with World Wide Web resources: An exploratory study using a holistic approach. Information Processing and Management, 36, 229-251.

\section{Submit your manuscript to a SpringerOpen ${ }^{\circ}$} journal and benefit from:

- Convenient online submission

- Rigorous peer review

- Immediate publication on acceptance

- Open access: articles freely available online

- High visibility within the field

- Retaining the copyright to your article 